\title{
Raman spectroscopy as a method for mineral identification on lunar robotic exploration missions
}

\author{
Alian Wang, Bradley L. Jolliff, and Larry A. Haskin \\ Department of Earth and Planetary Sciences and McDonnell Center for the Space Sciences \\ Washington University, St. Louis, Missouri
}

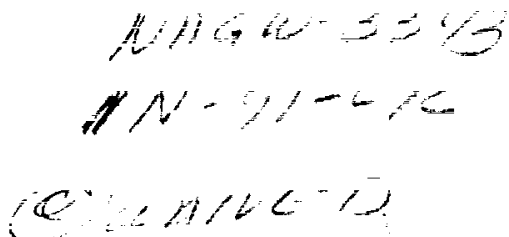

\begin{abstract}
The sharp, nonoverlapping Raman bands for plagioclase, pyroxene, and olivine would be advantageous for on-surface, active mineralogical analysis of lunar materials. A robust, light-weight, low-power, rover-based Raman spectrometer with a laser exciting source, entirely transmission-mode holographic optics, and a charge-coupled device (CCD) detector could fit within a $<20 \mathrm{~cm}$ cube. A sensor head on the end of an optical fiber bundle that carried the laser beam and returned the scattered radiation could be placed against surfaces at any desired angle by a deployment mechanism; otherwise, the instrument would need no moving parts. A modern micro-Raman spectrometer with its beam broadened (to expand the spot to $50-\mu$ m diameter) and set for low resolution $\left(7 \mathrm{~cm}^{-1}\right.$ in the $100-1400 \mathrm{~cm}^{-1}$ region relative to $514.5-\mathrm{nm}$ excitation), was used to simulate the spectra anticipated from a rover instrument. We present spectra for lunar mineral grains, $<1 \mathrm{~mm}$ soil fines, breccia fragments, and glasses. From frequencies of olivine peaks, we derived sufficiently precise forsterite contents to correlate the analyzed grains to known rock types and we obtained appropriate forsterite contents from weak signals above background in soil fines and breccias. Peak positions of pyroxenes were sufficiently well determined to distinguish among orthorhombic, monoclinic, and triclinic (pyroxenoid) structures; additional information can be obtained from pyroxene spectra, but requires further laboratory calibration. Plagioclase provided sharp peaks in soil fines and most breccias even when the glass content was high.
\end{abstract}

\section{Introduction}

Rover missions are continually being proposed for characterization of lunar and Martian surface material. Fundamental measurements include chemical composition and mineralogical composition. We suggest that Raman spectroscopy would be a very useful tool for in situ mineral identification that complements the capabilities of existing spectroscopic methods. The sharp, nonoverlapping Raman bands are better suited to the identification of specific silicates and minerals of other oxy-anion groups (e.g., carbonates, phosphates, sulfates) than are spectra obtained by most other methods. For some minerals, Raman bands also provide information on major cation substitutions, for example, $\mathrm{Mg}^{\prime}$ (defined as $\mathrm{Mg}^{2+} / \mathrm{Mg}^{2+}$ $\left.+\mathrm{Fe}^{2+}\right)$ ), an important petrologic parameter for lunar rocks. Recent developments in lasers, energy analyzers, and detectors make possible sensitive, physically robust Raman instruments of small volume, light weight, and low power.

In this paper, we show Raman spectra of lunar minerals, rock fragments, soils, and glasses taken with a modern spectrometer to simulate the spectra we could obtain from the lunar surface using a rover-compatible instrument. We compare these spectra with those anticipated from visible and nearinfrared, mid-infrared, and Mossbauer techniques. We then discuss briefly the instrumentation that would enable Raman analysis on a planetary surface.

Copyright 1995 by the American Geophysical Union.

Paper number 95JE02133.

0148-0227/95/95JE-02133\$05.00
Raman spectroscopy was used as an adjunct to infrared spectroscopy to investigate mineralogical characteristics of individual particles of lunar rocks, soils, and glasses from the Apollo missions. Fabel et al. [1972] showed that the mineralogical components (olivine, pyroxene, and feldspar) of individual lunar rock fragments were easily determined from the main peak positions of the Raman spectra. Perry et al. [1972] suggested that Raman peak shifts reflected cation ratios such as $\mathrm{Mg} / \mathrm{Fe}$ in lunar orthopyroxene and olivine. Several investigators [White et al., 1971; Fabel et al., 1972; Sweet et al., 1973] reported that Raman spectra of lunar glass particles were variable and unlike those obtained from synthetic silicate glasses. Many small, sharp peaks were discernible in the Raman spectra of some lunar glasses, indicating the presence of microcrystallites $(\alpha>3 \mathrm{~nm})$ [White et al., 1971; Fabel et al., 1972; Estep et al., 1972; Sweet et al., 1973]. We are unaware of any previously published Raman spectra of bulk lunar soils.

\section{Raman Spectra of Typical Lunar Materials}

\subsection{Instrument and Experimental Conditions}

To simulate the spectra we would expect from a roverbased Raman spectrometer, we used a modern micro-Raman spectrometer (Jobin-Yvon Company S3000 TM) with the 514.5-nm line of an $\mathrm{Ar}^{+}$laser as exciting source, CzemyTumer configuration, and a photodiode array as multichannel detector. To approximate the $200-\mu \mathrm{m}$ spot we suggest for the rover system, we severely degraded the capability of the instrument by using a microscope objective with a low magnification ( $20 \times$ Leitz, NA $=0.3$ ) to obtain a spot $50 \mu \mathrm{m}$ in diameter, and a 600 line $/ \mathrm{mm}$ grating and slit settings that yielded 
a spectral resolution of $7 \mathrm{~cm}^{-1}$ in the $100-1400 \mathrm{~cm}^{-1}$ region relative to the $514.5-\mathrm{nm}$ line. In the following discussions of mineral, rock, and soil spectra, a difference of $\pm 2 \mathrm{~cm}^{-1}$ or greater in peak position can be regarded as significant (measurement precision). Also, based on frequency calibration, peak positions are accurate to about $\pm 2 \mathrm{~cm}^{-1}$. Lunar rock chips or soils $(<1 \mathrm{~mm}$ fines) were placed on glass slides to simulate measurement in situ. For each such sample, measurements from several $50-\mu \mathrm{m}$ spots were added together to simulate the spectrum from a single large spot. For each measurement, $7 \mathrm{~mW}$ of laser power were used over a time of 1 to $10 \mathrm{~min}$ (consistent with requirements of low power consumption for a rover instrument). Spectra of at least the same quality should be obtainable by the suggested rover Raman system.

\subsection{Raman Spectral Characteristics of Common Lunar Minerals}

When monochromatic light strikes a sample, both elastic and inelastic scattering of photons occur. Elastically (Rayleigh) scattered radiation has unchanged frequency. Most inelastically scattered photons have lower frequencies (the Stokes Raman shift $\Delta v=v_{0}-v$, given here in wavenumber, $\mathrm{cm}^{-1}$ ) whose energy differences $\Delta v$ from the exciting line $v_{0}$ correspond to vibrational and rotational excitations in the scattering medium. Thus in general, Raman spectra are frequency-shift spectra, taken in visible wavelengths, whose patterns (the number, the positions, and the relative intensities of peaks) are a direct consequence of the structural symmetry of the scattering medium. Additionally, in some minerals, the frequencies of some specific Raman peaks are sensitive to compositional variations such as cation substitutions. Therefore Raman spectra can be used to identify minerals and to provide semiquantitative determination of mineral proportions as well as some information on mineral compositions.

Figure 1 shows Raman spectra of lunar plagioclase, pyroxene, and olivine. These common silicate minerals, in combination, constitute $>90 \%$ by volume of most lunar rocks. Each mineral yields a characteristic narrowband spectrum in the visible region of the spectrum that provides simple, unambiguous mineral identification and, in some cases, compositional and structural information. It is noteworthy that the major peaks for these minerals have quite narrow peak widths $\left(<20 \mathrm{~cm}^{-1}\right)$ distributed across a wide spectral region $(>900$ $\mathrm{cm}^{-1}$ ) and thus do not overlap. More detailed comments on the Raman spectra of individual minerals follow:

Olivine. Spectra of olivines $\left[\mathrm{Mg}_{2} \mathrm{SiO}_{4}\right.$ (forsterite, $\mathrm{Fo}$ ) $\mathrm{Fe}_{2} \mathrm{SiO}_{4}$ (fayalite, $\mathrm{Fa}$ ) solid solutions] in the compositional range typical of lunar samples $\left(\mathrm{Fo}_{30-75}\right.$, [e.g., Papike et al., 1991]) show two peaks in the $800-900 \mathrm{~cm}^{-1}$ region produced by the symmetric stretching vibration of the $\mathrm{SiO}_{4}$ group $\left(v_{1}\right.$ mode) in the olivine structure [Wang et al., 1994]. From peak frequencies, which shift linearly with $\mathrm{Mg} /(\mathrm{Fe}+\mathrm{Mg})[$ Guyot et al., 1986], we determined the forsterite content of the olivine grain taken from sample 76501 soil (Figure 1) to be in the range $\mathrm{Fo}_{50 \pm 10}$. On the basis of its composition, the olivine grain whose spectrum is shown in Figure 1, although extracted from a highland soil, is of mare basalt origin.

Feldspar. Typical lunar feldspar is calcic plagioclase $\left[\mathrm{CaAl}_{2} \mathrm{Si}_{2} \mathrm{O}_{8}\right.$ (anorthite, $\mathrm{An}$ ) - $\mathrm{NaAlSi}_{3} \mathrm{O}_{8}$ (albite, $\mathrm{Ab}$ ) solid solutions], with compositions ranging from $\sim A n_{65}$ to $A n_{98}$ [e.g., Papike et al., 1991]. Potassium feldspar [albite $\mathrm{KAlSi}_{3} \mathrm{O}_{8}$ (orthoclase, $\mathrm{Or}$ ) $-\mathrm{BaAl}_{2} \mathrm{Si}_{2} \mathrm{O}_{8}$ (celsian) solid solu-

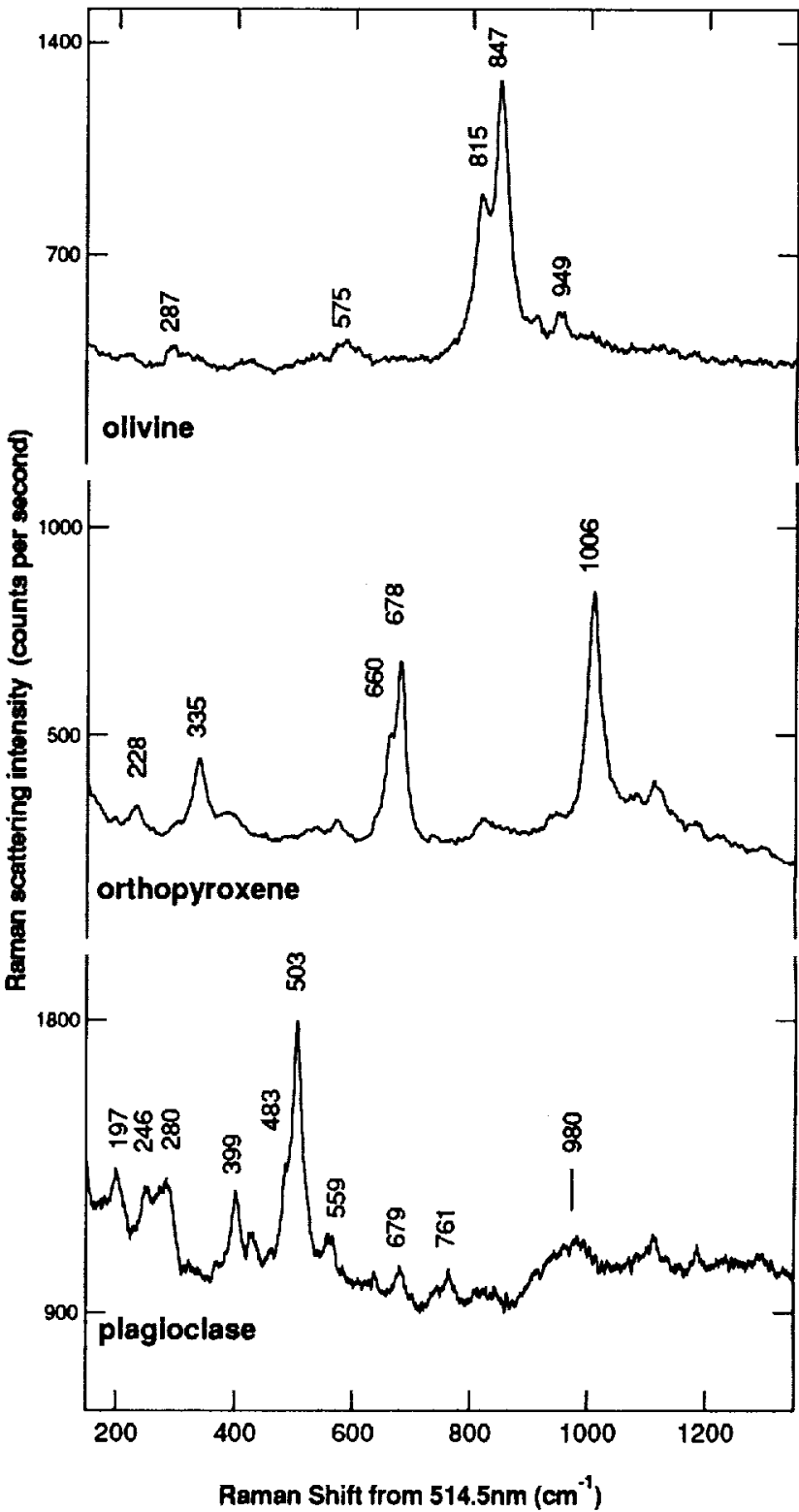

Figure 1. Raman spectra of olivine (a grain from soil sample 76501 ), orthopyroxene (in a thin section of sample 14161 , 7062 ), and plagioclase (in a thin section of 67503,7012 ). Sample 14161,7062 is a coarse-grained impact-melt rock of KREEP-like composition, and 67513,7012 is a fragment of gabbronorite.

tions] is an accessory mineral in most lunar rocks, but it is a major constituent of granite, a rare but important lunarhighland rock type. The two feldspars are easily distinguished by their Raman spectra (doublet for plagioclase, and triplet for $\mathrm{K}$-feldspar, in the region $450-520 \mathrm{~cm}^{-1}$, Table 1). Plagioclase feldspars have a double peak near $483 \mathrm{~cm}^{-1}$ and $503 \mathrm{~cm}^{-1}$ arising from lattice vibrational modes of the tectosilicate framework [Wang et al, 1994]. Figure 1 shows the Raman spectrum of a feldspar grain from a thin section of a highland gabbronorite fragment, 67513,7012 . In a series of standard terrestrial plagioclases with anorthite contents from $A n_{96}$ to $\mathrm{An}_{10}$, we found no systematic shift in the position of the doublet that correlated with An content. We found some systematic differences in positions and spectral patterns of weak peaks in the lower-frequency part of the spectra, but we would 
Table 1. Principal Raman Peaks of Lunar Minerals

\begin{tabular}{ll}
\hline Mineral Phases & Principal Raman Peaks, $\mathrm{cm}^{-1}$ \\
\hline Olivine & $-856, \sim 826$ \\
Orthopyroxene & $1006,678,660$ \\
Clinopyroxene & 1005,665 \\
Plagioclase & 503,483 \\
Ilmenite & $-600-700$ \\
Quartz & $465,207,128$ \\
K-feldspar & $513,475,454$ \\
Apatite & $1080,965,580,430$ \\
Zircon & $1008,977,440$ \\
Spinel & $770,670,409$ \\
Chromite & 680,550 \\
Ulvơspinel & $400,280,218$ \\
RE-Whitlockite & 970 \\
\hline
\end{tabular}

expect them to be obscured in the spectra of polymineralic lunar samples. The average position of the dominant plagioclase peak in the spectra shown in this paper is $504 \pm 1.4 \mathrm{~cm}^{-1}$, constant within the precision of our measurements.

Pyroxene and pyroxenoid. Lunar pyroxenes are compositionally and structurally more complex than olivines, and come in low-Ca varieties $\left[\mathrm{Mg}_{2} \mathrm{Si}_{2} \mathrm{O}_{6}\right.$ (enstatite, En) - $\mathrm{Fe}_{2} \mathrm{Si}_{2} \mathrm{O}_{6}$ (Ferrosilite, Fs) solid solutions] containing a few percent of $\mathrm{Ca}_{2} \mathrm{Si}_{2} \mathrm{O}_{6}$ (wollastonite, Wo), and high-Ca varieties (higher proportions of Wo). Different pyroxene structures (orthorhombic, monoclinic, and triclinic pyroxenoid) may produce different and unique Raman spectral patterns (this work and Dele-Dubois et al. [1981]), but full determination of effects of composition and structure remains to be done. The upper three of the pyroxene-pyroxenoid spectra shown in Figure 2 were taken from a single, large $(500 \mu \mathrm{m})$ pyroxene grain in a thin section of 14161,7062, an impact-melt rock of KREEPbasalt composition [Jolliff et al., 1991]. This grain is known from electron probe microanalysis to be zoned from an orthopyroxene core (orthorhombic enstatite, $\mathrm{En}_{80} \mathrm{Wo}_{3}-\mathrm{En}_{65} \mathrm{Wo}_{5}$ ), through a thick zone of (monoclinic) pigeonite that becomes progressively $\mathrm{Fe}$ rich away from the core $\left(\mathrm{En}_{59} \mathrm{Wo}_{15}\right.$ to $\mathrm{En}_{30} \mathrm{Wo}_{15}$ ), to a thin overgrowth of pyroxferroite (a pyroxenoid, triclinic, $\mathrm{Mg}^{\prime} \sim 0.05$ ). The orthopyroxene portion has a double peak in its Raman spectrum at 660 and $678 \mathrm{~cm}^{-1}$ in the $660-680 \mathrm{~cm}^{-1}$ region (the $\mathrm{Si}-\mathrm{O}_{\mathrm{b}}-\mathrm{Si}$ bond symmetric stretching vibrational mode [Wong et al, 1994]; $\mathrm{O}_{\mathrm{b}}$ refers to bridging oxygen, $\mathrm{O}_{\mathrm{n}}$ to nonbridging oxygen). The orthopyroxene portion of the inverted pigeonite from 67513,7012 also has a double peak in the $660-680 \mathrm{~cm}^{-1}$ range, at 650 and $666 \mathrm{~cm}^{-1}$, but at lower frequency $\left(997 \mathrm{~cm}^{-1}\right)$ than the orthopyroxene portion of $14161,7062\left(1006 \mathrm{~cm}^{-1}\right)$ for the peak in the 990-1020 $\mathrm{cm}^{-1}$ range, the region of the Si- $\mathrm{O}_{\mathrm{nb}}$ symmetric stretching vibrational mode [Wang et al., 1994]. The pigeonite and pyroxferroite of 14161,7062 have only a single peak each in the $660-680 \mathrm{~cm}^{-1}$ region, at 665 and $661 \mathrm{~cm}^{-1}$. Their peak positions differ in the $990-1100 \mathrm{~cm}^{-1}$ range, with pyroxferroite at $994 \mathrm{~cm}^{-1}$ and pigeonite at $1005 \mathrm{~cm}^{-1}$. The pyroxferroite peaks rest on a hump produced by mild fluorescence. The spectrum of an augite (clinopyroxene) grain in a thin section of highland lithic fragment 67513,7012 has a single peak in the $\mathrm{Si}_{1}-\mathrm{O}_{6}-\mathrm{Si}$ stretching vibrational region at $663 \mathrm{~cm}^{-1}$ and another in the Si$\mathrm{O}_{\mathrm{nb}}$ stretching vibrational region at $1010 \mathrm{~cm}^{-1}$. Minor spectral differences among the various pyroxenes also occur in the $200-400 \mathrm{~cm}^{-1}$ region (lattice vibrational modes); the value of those less intense peaks to in situ sensing of polyphase mixtures remains to be tested. The pyroxene spectra contain much information, but we do not yet know how to interpret all of the differences we see.
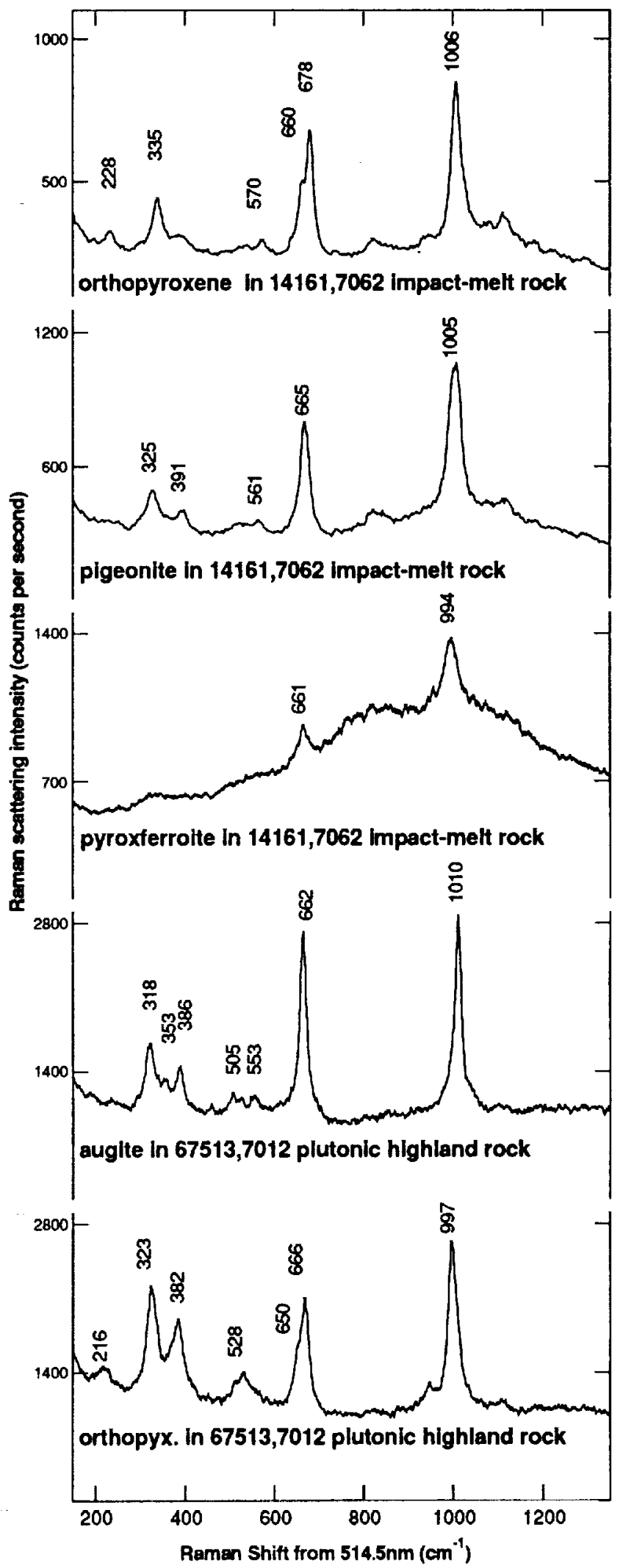

Figure 2. Raman spectra of pyroxene grains. The upper three spectra are from a single, zoned grain (orthorhombic $\rightarrow$ monoclinic $\rightarrow$ triclinic pyroxene) in impact-melt rock 14161, 7062. Note the broad fluorescence swell beneath the peaks of the pyroxenoid (pyroxferroite). The lower two spectra are from two separate pyroxene grains (augite and an exsolved, partly inverted pigeonite grain) in sample 67513,7012 , a fragment of a slowly cooled, highland plutonic igneous rock. 
Ilmenite and other oxides. Ilmenite is the most abundant oxide mineral in lunar samples, especially in mare basalts. In Raman spectral measurements taken on ilmenite grains in lunar samples, we observed no obvious spectral peaks. In a Raman study of opaque and semi-opaque minerals, Pinet et al. [1986] found only a weak, broad peak in the $600-700 \mathrm{~cm}^{-1}$ region, and a spectrum from a terrestrial ilmenite taken in our lab shows the same characteristics. We did not observe ilmenite in our comparatively high-background spectrum of a mare basalt fragment (discussed below). The spinels, e.g., chromite, pleonaste, and ulvospinel, are also widespread oxide minerals of minor abundance on the Moon; their main Raman peaks are listed in Table 1. We did not observe them in our soils and rock fragments.

Accessory minerals. Quartz, apatite, whitlockite, zircon, and other accessory minerals also have distinctive Raman spectra. Although we do not expect to observe these spectra in analyses of typical lunar surface materials, if the laser beam were to strike an individual, large grain, it would be readily identifiable. Table 1 lists the main Raman peaks of some of the more common lunar accessory minerals.

We can hardly regard the Moon as thoroughly explored. It may be that concentrates of minerals other than olivine, pyroxene, and plagioclase feldspar will be encountered during robotic explorations. Raman spectroscopy may be the most sensitive reasonable means of discovering their presence.

\subsection{Raman Spectra of Lunar Soils and Rock Fragments}

In order to demonstrate the first-order characteristics of Raman spectra that could be obtained from surface sensing of lunar soils and rocks, we analyzed $<1 \mathrm{~mm}$ fines representing three common types of lunar soil, and individual rock fragments that represent the major lithologic components of those soils. The soil types are anorthositic highland soil, represented by sample 67511 ; high-Ti mare-basalt soil, represented by sample 71501; and mixed highland soil of approximately noritic normative composition (mineralogy estimated from chemical composition), represented by samples 76501 and 73241 (which differ significantly in their lithologic components). Soil $67 \overline{1} 1$ is a plagioclase-rich, immature soil $\left(\mathrm{I}_{\mathrm{S}} \mathrm{FeO}=8.8\right.$ [Morris, 1978]) consisting mainly of brecciated, plagioclase-rich rocks and glass. Soil 76501 is a submature mixture $\left(\mathrm{I}_{\mathrm{s}} \mathrm{FeO}=58\right.$ [Morris, 1978]) of noritic impact-melt breccia, mare basalt, and relatively anorthositic components. Soil 73241 is immature $\left(\mathrm{I}_{\mathrm{S}} / \mathrm{FeO}=18\right.$ [Morris, 1978]) and consists mostly of comminuted noritic impact-melt breccia. The rock fragments include particles of anorthosite and darkmatrix breccia from sample 67513, and a noritic impact-melt breccia and a high-Ti mare basalt from 76503. Each of these is a lithic fragment from 2 to $4 \mathrm{~mm}$ sieved splits of soil samples (67510 and 76500) parental to 67511 and 76501 . Chemical compositions and some relevant mineralogical parameters of the soils are given in Table 2 .

To simulate bulk Raman analyses based on the larger sized laser spot anticipated for the rover instrument, we added together spectra from $6-15$ individual $\sim 50$ - $\mu \mathrm{m}$ spots for each soil sample and from fewer spots for each rock fragment. The results do not simulate the expected rover-based spectra precisely; too few spots were analyzed, and linear additivity of spectra was not demonstrated. We sought only to demonstrate the types of useful and important mineralogical information that can be obtained. An unintended advantage of this approach is that we can observe specific mineral components in the individual $50 \mu \mathrm{m}$ spot spectra, which aids our understanding of the origins of lines in the summed spectra.

Significant differences among the spectra of the three soils reflect different proportions of major silicate minerals. The spectrum of anorthositic soil 67511 is dominated by peaks from plagioclase (Figure 3), the principal mineral in all Apollo 16, station 11 soils. It shows mild fluorescence of undetermined origin at higher wavenumbers and rather broad peaks in the regions expected for pyroxene. Some $20 \%$ of the soil consists of $\mathrm{Fe}$ - and $\mathrm{Mg}$-bearing pyroxene grains in relict igneous lithic fragments and melt-breccia fragments [Jolliff and Haskin, 1995]. Three of the 10 individual spectra making up the composite show weak pyroxene peaks of the type expected for glassy to very finely crystalline (cryptocrystalline) melt-breccia matrix, which produces weak Raman scattering.

The spectrum of soil 71501 shows strong peaks for pyroxene and plagioclase, and weak peaks for olivine, consistent with derivation of the soil mainly from high-Ti mare basalt (a predominantly pyroxene-plagioclase-ilmenite rock). The positions of the olivine peaks indicate a value of $\mathrm{Fo}_{75 \pm 10}$, consistent with the relatively magnesian range of olivine in Apollo 17 high-Ti basalts [Papike et al., 1991]. Individual spectra (not shown) from soil 71501 reveal at least two distinct py-

Table 2. Soil Compositions and Petrography

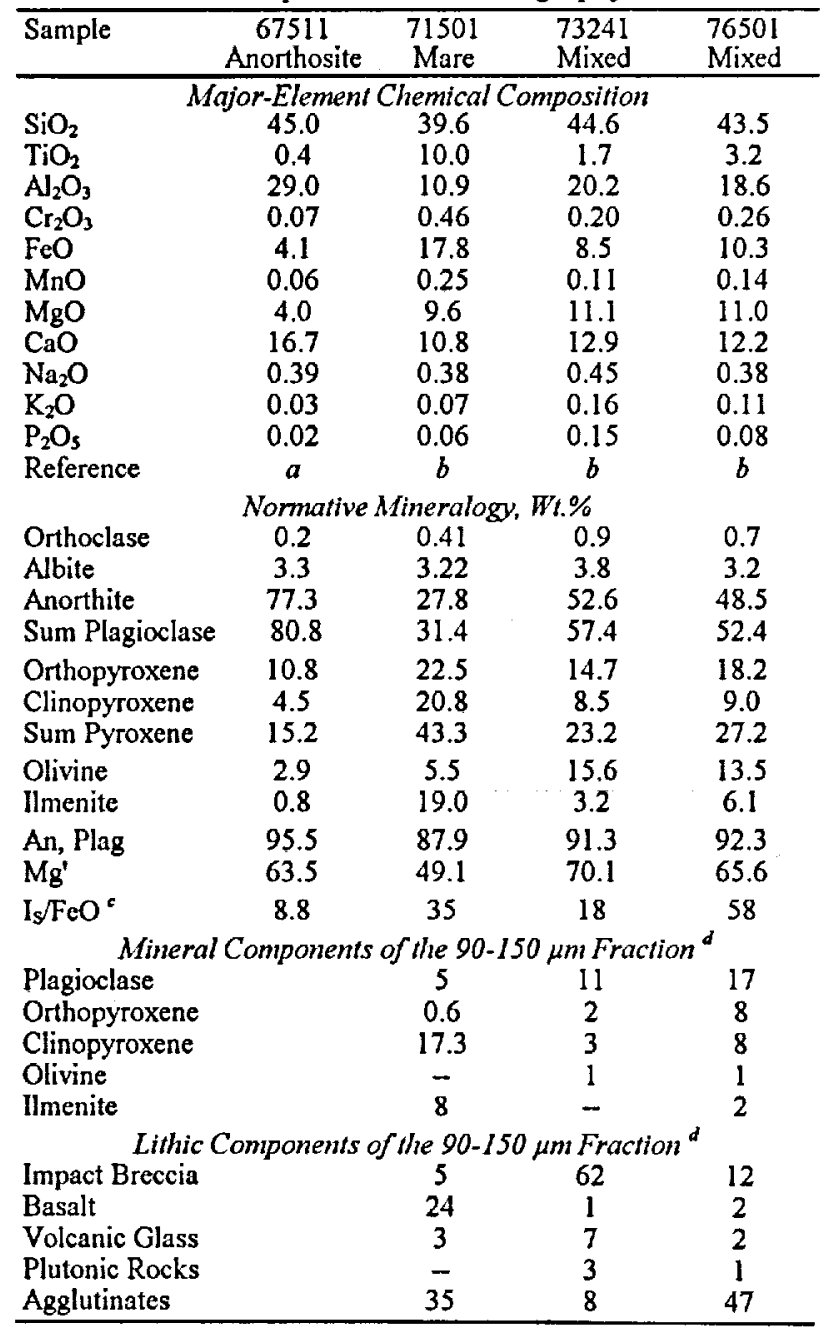

Korotev [1982]

Wolfe et al. [1981].

c Morris et al. [1983].

Heiken and McKay [1974]. 
roxenes. The peak positions are consistent with the presence of mainly clinopyroxenes, as expected for a mare soil.

The composite spectra of noritic soils 76501 and 73241 also contain peaks for pyroxene, plagioclase, and olivine, with olivine more abundant than in the mare soil. Plagioclase and pyroxene are the principal observed mineral constituents of the soils (Table 2). The peaks in the spectra of the noritic soils are not as sharp as those in the spectrum of mare soil 71501, which (in our subsample) was coarser in grain size. The
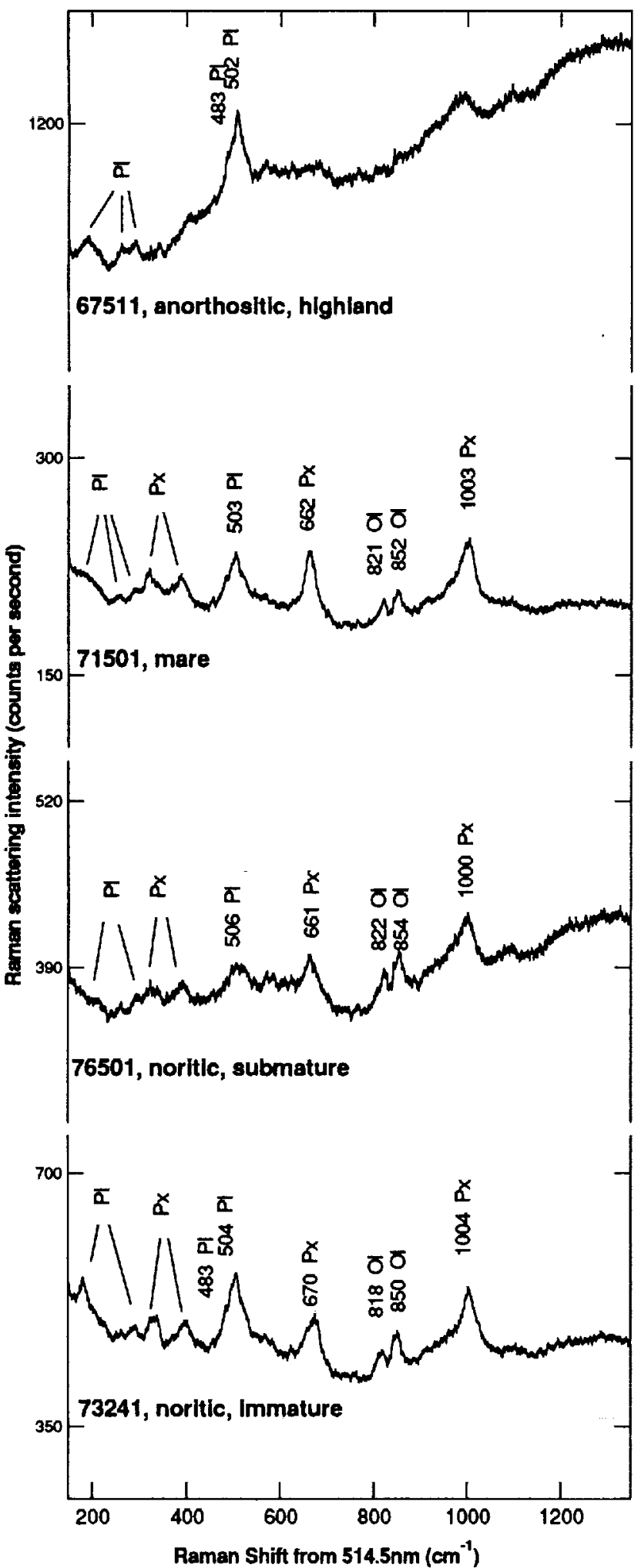

broader peaks may arise from the spread of olivine compositions and pyroxene structural types, consistent with the diversity of rock types known to be present in these soils [e.g., Rockow et al., 1994]. Peak-to-background ratios are low compared to those obtained from the other soils, also consistent with the very fine-grained nature of breccia-matrix components that dominate these soils. Soil 76501 contains a higher proportion $(-50 \%)$ of agglutinates (glassy-matrix, clast-bearing particles) than $73241(\sim 10 \%)$, and this may contribute to its relatively weaker Raman scattering. The peak positions of olivine in soil 76501 correspond to the composition $\mathrm{Fo}_{85 \pm 10}$. The composition of olivine in troctolitic anorthosite of sample 76503 (2 to $4 \mathrm{~mm}$ rock fragments from the same parent soil as 76501) is known from electron probe microanalysis to be $\mathrm{Fo}_{88}$, in good agreement. The olivine peaks of 73241 soil indicate $\mathrm{Fo}_{65 \pm} 10$, in agreement with expectation from the normative value (Table 2) and resulting from abundant impact-melt breccia and the absence of the highly magnesian troctolitic-anorthosite component from this soil. Peak positions indicate that clinopyroxenes are more abundant than orthopyroxenes in the spectrum of 76501 , whereas orthopyroxene is more abundant in the spectrum of 73241. Without further systematic experiments, we cannot with confidence interpret pyroxene peak positions of such soils precisely.

The composite of four individual spectra taken for the anorthositic lithic fragment from 67513 (Figure 4) is similar to that of the anorthositic soil 67511 (Figure 3) (both from parent soil 67510 ), but has sharper plagioclase peaks, reflecting the coarser grain size within the lithic fragment. The spectrum of the dark-matrix breccia from 67513 also shows plagioclase as the dominant component, but has only weak peaks for olivine and no peaks for pyroxene. Despite their dark appearance, such breccias have bulk compositions indicating that their parent rocks were plagioclase-rich (e.g., 25-30\% $\mathrm{Al}_{2} \mathrm{O}_{3}$ ), and in thin section they reveal small plagioclase clasts set in a dark, glassy to cryptocrystalline matrix. The positions of the olivine peaks indicate $\mathrm{Fo}_{65 \pm 10}$, consistent with the relatively ferroan composition $\left(\mathrm{Mg}^{\prime}=0.63\right)$ of this soil (Table 2). The sharp-peaked Raman spectrum of the anorthositic lithic fragment from sample 67513 contrasts with the near-infrared spectrum of the similar, predominantly plagioclase-clastbearing $60019,215,3$ shown by Pieters and Taylor [1989, their Figure 8], which shows only a weak pyroxene absorption and a feature tentatively credited to ilmenite.

The composite spectrum of a lithic fragment of high-Ti basalt $(76503,7045$; Figure 4 ) is dominated by peaks of pyroxene and plagioclase. Peak positions indicate that the pyroxene is principally monoclinic. Olivine is absent from the spectrum and, based on the bulk composition of the lithic fragment, none would be expected. In contrast, the composite spectrum of soil 71501 (Figure 3) shows olivine peaks, consistent with its normative mineralogy and confirming that a high-Ti basalt

Figure 3. Raman spectra of four samples of lunar fines: 67511 , an immature, plagioclase-rich highland soil from near North Ray Crater (note the mild fluorescence across most of the spectrum); 71501, a submature mare soil (a slightly coarser-grained aliquot than the reported average for that soil) from the Taurus-Littrow Valley; 76501, a submature, mixed mare-highland soil from the base of the North Massif; and 73241 , an immature highland soil from the landslide area near South Massif. These and the spectra in subsequent figures are composites produced by adding together spectra from several $\sim 50-\mu \mathrm{m}$ spots to simulate roughly the spectra from the $\sim 200$ $\mu \mathrm{m}$ spots expected for a rover instrument. 
such as 76503,7045 was not its only lithologic component (Table 2).

The composite spectrum of noritic impact-melt breccia fragment 76503,7030 (Figure 4) shows a sharp peak for plagioclase and weak peaks for pyroxene and olivine. Individual
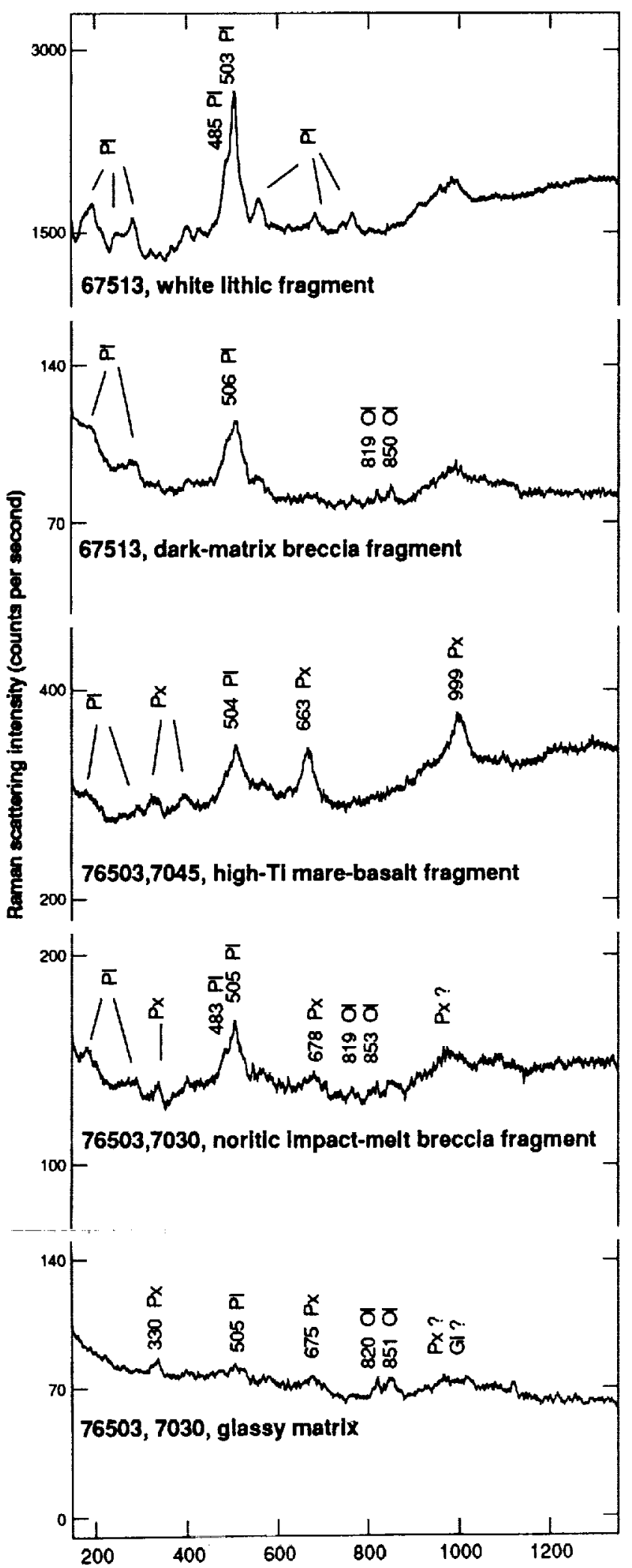

Raman Shift from $514.5 \mathrm{~nm}^{\left(\mathrm{cm}^{-1}\right)}$ spectra (not shown) are either dominated by plagioclase (present as unevenly distributed plagioclase clasts) or they consist of subequal olivine, pyroxene, and plagioclase peaks (typical of glassy to finely crystalline matrix). Peak positions of olivine indicate an average composition in the range $\mathrm{Fo}_{70-90}$. Peak positions of pyroxene are poorly defined but appear to be dominated by orthopyroxene. These features are consistent with mineralogy and mineral compositions of typical Apollo 17 impact-melt breccias. Several of the individual spectra from the noritic impact-melt breccia fragment 76503,7030 are from areas that are mainly matrix; the composite of these spectra is shown as 76503,7030 "glassy matrix" (Figure 4). Few mineral features are evident. Weak peaks are seen for plagioclase and pyroxene (again, apparently orthopyroxene). The stronger olivine peaks are essentially the same as those of the total composite of impact-melt breccia spectra.

These primary experiments show that Raman spectra enabled us to distinguish among rock types (e.g., mare basalt, impact-melt breccia) and to identify unambiguously the main mineral constituents of the soil and breccia fragments, thus providing a strong indication of the principal rock types parental to them (e.g., anorthositic suite, mare basalt, highland norite or troctolite, with some information on mafic-mineral cation proportions $\left(\mathrm{Mg}^{2+}, \mathrm{Fe}^{2+}\right.$, and $\left.\mathrm{Ca}^{2+}\right)$ ). Such mineralogical information is a crucial complement to bulk chemical composition in determining what rock types produced particular soils and breccias.

In order to optimize the information available from Raman spectra taken on the lunar surface, it will be necessary to quantify by laboratory measurement the effects of mineral proportions, grain size, glass contents and types (agglutinitic, breccia matrix, and volcanic), and other textural variables. For example, Raman scattering efficiencies decrease in the order olivine $>$ pyroxene $>$ plagioclase, a small quantity of olivine thus yields a disproportionately strong peak. Thus, to achieve semiquantitative Raman analysis of planetary surface materials, a series of relative Raman scattering efficiencies for appropriate minerals must be established. In addition, the effects of grain size and glass content must also be evaluated.

\subsection{Raman Spectra of Representative Lunar Glasses}

Because glassy materials are prevalent in the lunar regolith, we discuss briefly the Raman spectra of three fundamentally different kinds: volcanic glass, agglutinitic glass, and glassy matrix of impact breccias. Figure 5 shows the spectrum of a single spherule of pyroclastic green volcanic ash from sample 15426 [Steele et al., 1992]. The spectrum shows a broad hump centered near $950 \mathrm{~cm}^{-1}$, typical of orthosilicate glass (a

Figure 4. Raman spectra of lithic fragments from sample 67513 (from North Ray Crater, Apollo 16) and 76503 (North Massif, Apollo 17). The white lithic fragment consists essentially of plagioclase. That mineral dominates the spectrum of the companion breccia fragment which, despite its finegrained nature, shows both plagioclase and small olivine peaks. Plagioclase and pyroxene peaks of roughly equal height are seen in mare basalt fragment 76503,7045 , and fluorescence produces a rising background with increasing wavenumber, as in 67511 (Figure 3). The upper 76503,7030 composite spectrum contains all the individual spectra obtained on that breccia fragment, including some individual spectra dominated by plagioclase clasts, and the lower spectrum is a composite of two spectra that are mainly of the glassymicrocrystalline matrix. 


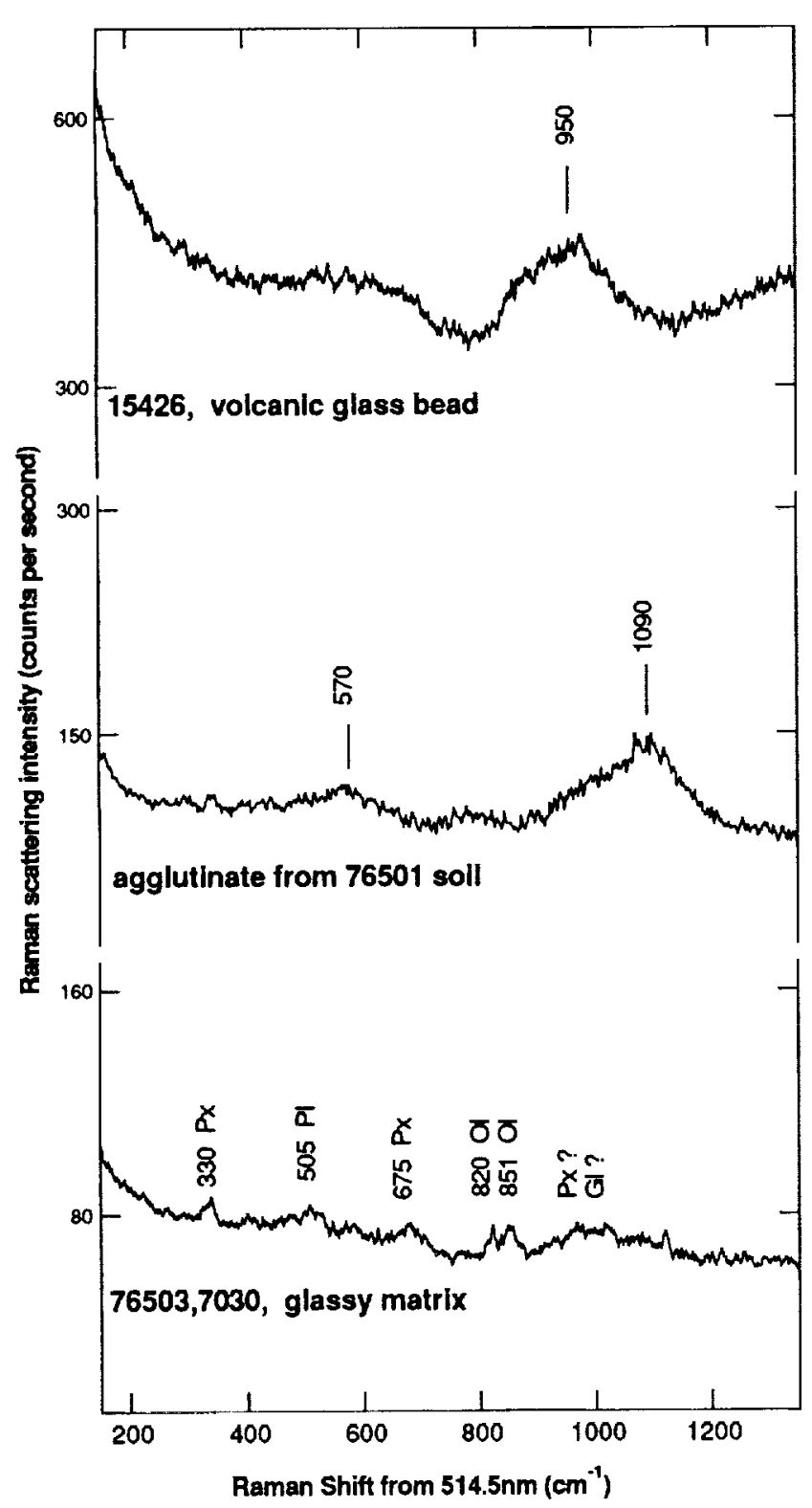

Figure 5. Lunar glass spectra contain broad features but no peaks if entirely glassy, as in the mare volcanic glass and the agglutinate.

high proportion of Si-O $\mathrm{On}_{\mathrm{nb}}[$ McMillan, 1984]), consistent with the high proportion of olivine in the normative composition. This Raman spectrum is similar to one shown by Perry et al. [1972], except we observe no peaks for olivine in this particular bead, indicating that it consists entirely of glass, and the background at low wavenumbers is greater in our spectrum.

Several individual spectra from soil 76501 were mainly of agglutinates, i.e., small particles that consist of glass produced by micrometeorite impacts plus mineral and lithic grains included as clasts. These (combined) spectra have a broad, weak band centered at $\sim 570 \mathrm{~cm}^{-1}$, and a stronger, broad band centered at $\sim 1090 \mathrm{~cm}^{-1}$ (Figure 5). These positions are consistent with an Al-Si-rich tectosilicate glass structure with most of the oxygen present in $\mathrm{Si}-\mathrm{O}_{b}-\mathrm{Si}$ bonds [MCMillan, 1984]. We have already discussed the spectrum of glassy matrix from breccia fragment 76503,7030 . We repeat the spectrum in Figure 5 for ease of comparison with the spectra of the other glassy materials.

\subsection{Comparison of Spectroscopic Methods Used (or Proposed) for Lunar Mineralogy}

Remote sensing of lunar soils so far has been done mainly by visible and near-infrared reflectance spectroscopy (VISNIR, 0.3 to $2.6 \mu \mathrm{m}, 4000$ to $30,000 \mathrm{~cm}^{-1}$ [e.g., Pieters, 1986, 1993]) from Earth or from orbit. Laboratory work [Nash et al., 1993] and Earth-based telescopic observation [Bell et al., 1995] have extended the spectral range into the mid-infrared (MIR, 4-12 $\mu \mathrm{m}, \sim 800$ to $2500 \mathrm{~cm}^{-1}$ ). Both of them are also considered for on-surface use. Mosssbauer spectroscopy has been proposed as a mineral indicator, especially for $\mathrm{Fe}$ bearing minerals [e.g., Morris et al., 1992], and has been chosen for future rover missions on Mars. We would propose Raman spectroscopy for on-surface rover missions, combined with Mossbauer spectroscopy, to obtain in situ mineral identification and rough mineral proportions for silicates, $\mathrm{Fe}$ oxides, carbonates, sulfates, and phosphates, the main mineral phases on lunar and Martian surfaces. Figure 6 summarizes the differences among these spectroscopic methods proposed for on-surface mineralogical application in three aspects: spectral mechanism, actual spectral features, and mineralogy of a mixture. Each technique has strengths and weaknesses; thus a synergistic combination of spectroscopic techniques, as well as compositional analysis techniques, is needed to achieve a comprehensive characterization of planetary surface materials.

Figure 7 shows a reflectance spectrum for a mature mare soil region of the Moon [Pieters, 1978] as commonly obtained by VIS-NIR remote sensing. The broad absorption peak at $\sim 10,000 \mathrm{~cm}^{-1}$ can be enhanced by removal of a continuum, as shown in Figure 7. The principal, broad feature is produced by a $d$-electron transition involving $\mathrm{Fe}^{2+}$ ions in pyroxene [Burns, 1993]. Olivine produces a broader, triple peak at lower energy, while the plagioclase peak (whose mechanism of production is debatable) is even lower and much weaker. Although the principal absorption features of these minerals can be distinguished individually, they overlap strongly in the spectrum of a mixture. Therefore, curve fitting is required for phase identification from the spectrum of a soil (e.g., for Opx + Cpx mixtures, see Sunshine and Pieters [1993]). Additionally, the interpretation of the proportion of pyroxene or olivine from a VIS-NIR spectrum requires an assumption about the Fe content.

Mid-infrared reflectance spectroscopy, as proposed for lunar remote sensing [Nash et al., 1993], measures vibrational energies of silicate frameworks. The multipeak, broad bands in single-mineral spectra of Figure 8 result from the overlap of bands from fundamental vibrational modes and other bands of similar intensity from overtone and combination modes. In contrast, Raman peak intensities of overtone and combination modes are 1 to 2 orders of magnitude weaker than those of fundamental vibrational peaks, which results in sharper peaks and simpler spectral patterns. The typical full width at half height for Raman spectra is $\sim 5-20 \mathrm{~cm}^{-1}$, compared with MIR peak widths exceeding $200 \mathrm{~cm}^{-1}$ for the $\mathrm{Si}-\mathrm{O}_{\mathrm{nb}}$ asymmetric stretching vibrations ( $v_{3}$ mode, IR active) of olivine, orthopyroxene, clinopyroxene, feldspar, and quartz, all of which occur in the $700-1300 \mathrm{~cm}^{-1}$ range. In single-mineral spectra, the MIR peaks in this range can be used effectively for silicatemineral identification. The bands for these minerals overlap extensively, however, complicating mineral identification and quantification of lunar soil spectra. It is also more difficult instrumentally to work in the MIR spectral range than in the visible range. The sensitivity of MIR to hydrous components, 


\begin{tabular}{|c|c|c|c|c|}
\hline comparison terms & VIS-NIR spectroscopy & ${ }^{57} \mathrm{Fe}$ Mossbauer spectroscopy & Raman Spectroscopy & Mid-IR spectroscopy \\
\hline $\begin{array}{l}\text { Spectral mechanism } \\
\text { Transition entity }\end{array}$ & Mainly d-electrons of $F_{\theta}$ & Fe nudeus & \multicolumn{2}{|c|}{ Chemical bonds \& cystal lattice } \\
\hline Information provided for & $\begin{array}{l}\text { Principally Fe-bearing } \\
\text { phases }\end{array}$ & $\begin{array}{l}\text { Only Fe-bearing } \\
\text { phases }\end{array}$ & \multicolumn{2}{|c|}{$\begin{array}{l}\text { Silicates, carbonates, \& other }\left(\mathrm{MO}_{\mathrm{x}}\right) \text {-bearing } \\
\text { phases, aiso most oxides \& sulfides, but not } \\
\text { metals }\end{array}$} \\
\hline $\begin{array}{l}\text { Actual spectral features } \\
\text { Spectral overlap in mixture }\end{array}$ & Yes & $\begin{array}{c}\text { Yes } \\
\text { for non-metallic phases }\end{array}$ & No & Yes \\
\hline $\begin{array}{l}\% \text { of average peak-width in } \\
\text { a common spectral reglon }\end{array}$ & $\begin{array}{l}20 \% \\
0.5 \mu \mathrm{m} \text { in } 2.3 \mu \mathrm{m} \\
\text { (VIS-NIR) }\end{array}$ & $\begin{array}{l}25 \% \\
0.3 \mathrm{~mm} / \mathrm{s} \text { in } 1.2 \mathrm{~mm} / \mathrm{s} \\
(\gamma \text { ray })\end{array}$ & $\begin{array}{c}<5 \% \\
20 \mathrm{~cm}^{-1} \text { in } 900 \mathrm{~cm}^{-1} \\
\text { (VIS) }\end{array}$ & $\begin{array}{l}30 \% \\
200 \mathrm{~cm}^{-1} \text { in } 600 \mathrm{~cm}^{-1} \\
\text { (mid-IR) }\end{array}$ \\
\hline $\begin{array}{l}\text { Mineralogy of a mixture } \\
\text { Phase identification -- } \\
\text { silicates } \\
\text { oxides }\end{array}$ & $\begin{array}{l}\text { Possible } \\
\text { w/ curve fitting (develop.) } \\
\text { - }\end{array}$ & $\begin{array}{l}\text { Yes } \\
\text { w/ ourve fitting (available) } \\
\text { w/ curve fitting (available) }\end{array}$ & $\begin{array}{l}\text { Yes } \\
\text { directly from raw data } \\
\text { difficult for some }\end{array}$ & $\begin{array}{r}\text { Difficult } \\
\text { curve fitting (?) } \\
\text { - }\end{array}$ \\
\hline Mineral proportions -- & $\begin{array}{l}\text { Possible } \\
\text { MGM method }\end{array}$ & $\begin{array}{l}\text { Yes } \\
\% \text { in Fe } \theta_{\text {tow }} \text { associated in } \\
\text { mineral phases, if relative f } \\
\text { factors are established }\end{array}$ & $\begin{array}{l}\quad \text { Yes } \\
\text { mol. \% in total for } \\
\left(\mathrm{MO}_{\mathrm{x}}\right) \text {-bearing } \\
\text { phases, if relative } \sigma \\
\text { are established }\end{array}$ & - \\
\hline
\end{tabular}

Figure 6. Comparison of spectroscopic methods proposed for on-surface mineralogical investigation of the Moon. For the application of the modified Gaussian model (MGM) to quantification of VIS-NIR spectra, see Sunshine and Pieters [1993]. For determining mineral proportions by Mossbauer spectroscopy, $f$ is the recoilfree factor, in Raman spectroscopy, $\sigma$ refers to the scattering cross section.

however, is attractive nevertheless for detecting some specific minerals and atmospheric compositions of planets.

Recently, reflectance ${ }^{57} \mathrm{Fe}$ Mössbauer spectroscopy has been proposed for mineral identification on planetary landers and rovers [e.g., Morris et al., 1992]. The positions and intensities of Mosssbauer peaks reflect the influence of electron configuration on nuclear transitions. Mossbauer spectroscopy

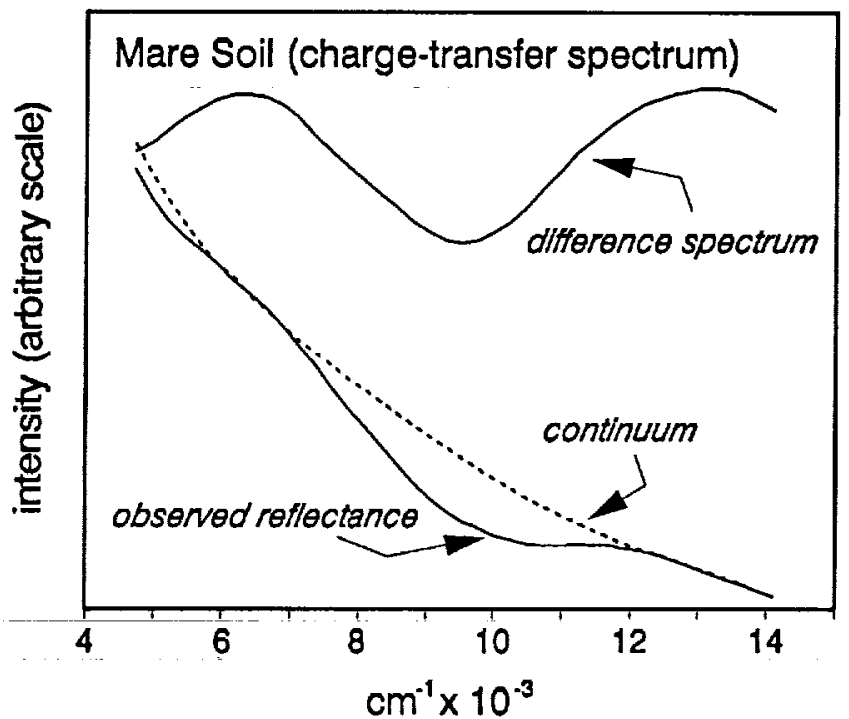

Figure 7. Visible-near-infrared spectrum of a mare soil [after Pieters, 1978]. The lower curve shows the observed reflectance in this energy range and the continuum that was removed to provide the difference spectrum with its enhanced absorption peak. Compare the width of the peak with those of the sharper Raman bands of Figure 1. using a ${ }^{57} \mathrm{Fe}$ source senses iron-bearing minerals and provides information on the valence state of $\mathrm{Fe}\left(\mathrm{Fe}^{0}\right.$ and $\mathrm{Fe}^{2+}$ for lunar glass and minerals) and on $\mathrm{Fe}^{2+}$ occupancy of different crystallographic sites (e.g., M1 and M2 sites in pyroxene). Figure 9 shows a (transmission) Mössbauer spectrum of iron species in lunar soil 10084 , obtained over a velocity range of $\pm 8 \mathrm{~mm} / \mathrm{s}$. Mössbauer doublets of olivine, pyroxene, glass, and ilmenite are located near each other in two narrow energy ranges $(-0.4$ to $0.8 \mathrm{~mm} / \mathrm{s}$ and

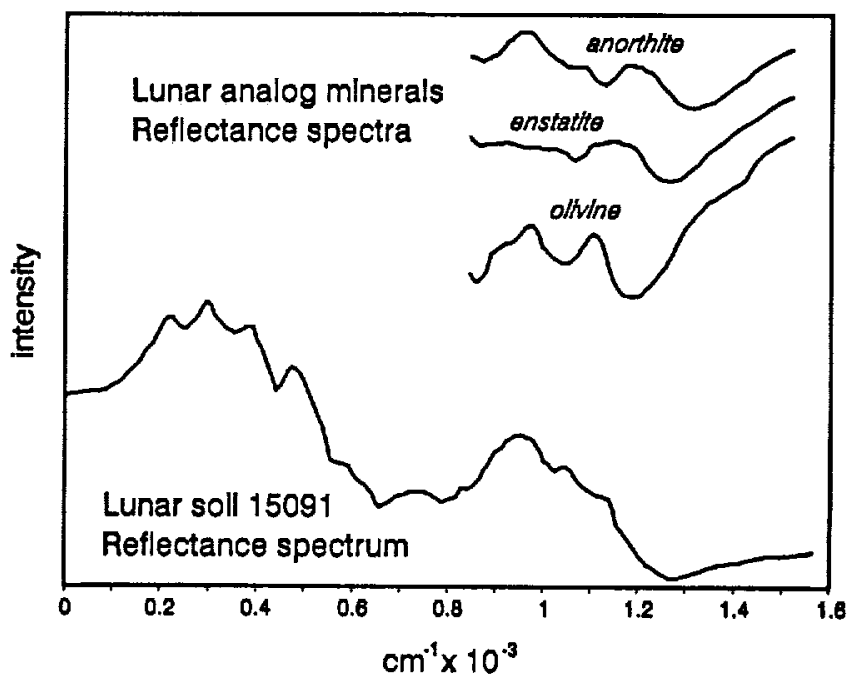

Figure 8. Mid-infrared reflectance spectra for lunar-simulant minerals [after Nash et al., 1993] and a lunar mare soil [after Perry et al., 1972]. Note the distinctive spectra of the individual minerals, but also their peak overlaps, which contribute to the complexity of the soil spectrum. 


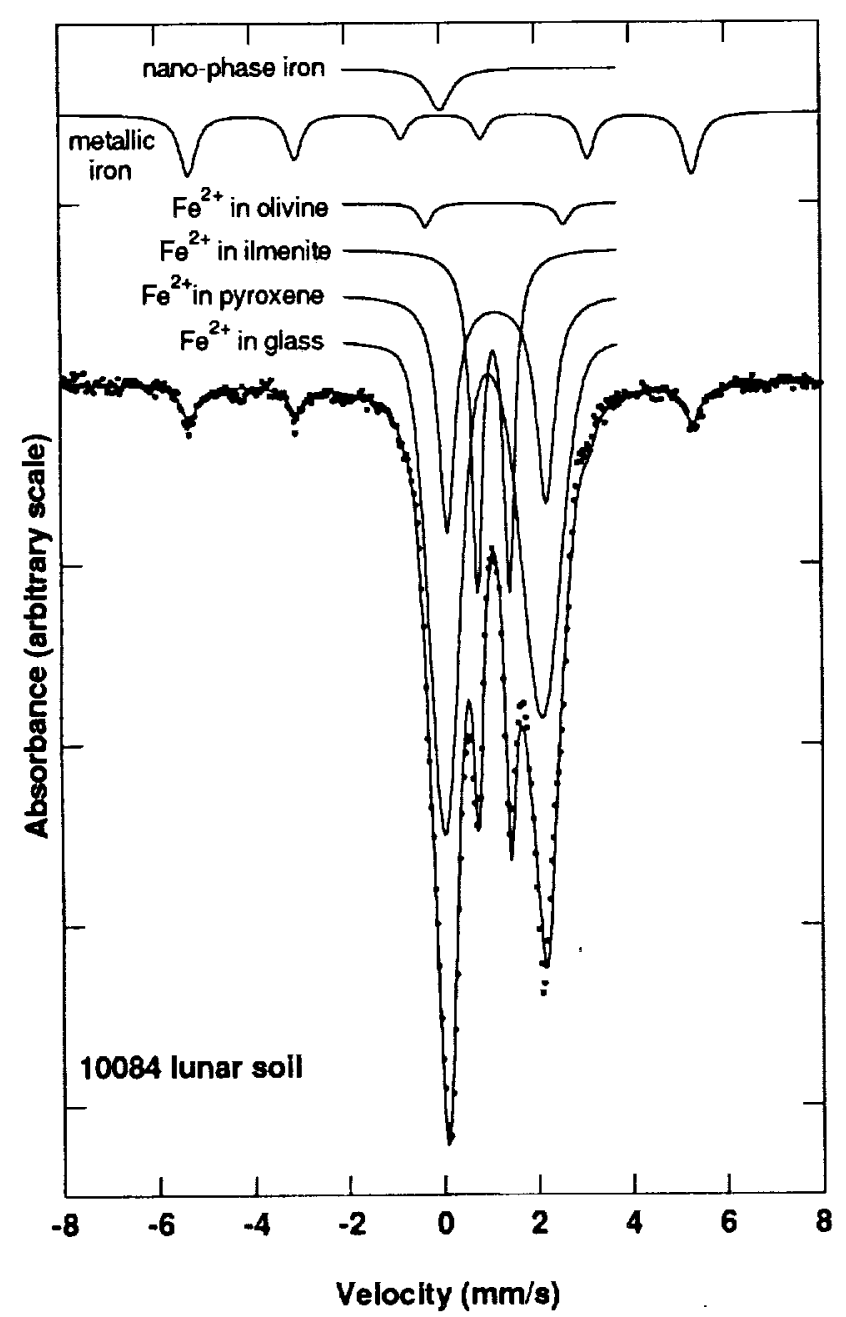

Figure 9. Mössbauer transmission spectrum for lunar soil 10084 , showing a typical deconvolution into four doublets, a sextet, and a singlet (data courtesy of R. V. Morris). Ilmenite and two forms of iron metal, seen here, are not observed in lunar soils by Raman and infrared techniques.

1.4 to $2.6 \mathrm{~mm} / \mathrm{s}$ ), and typical peak widths are $-0.3 \mathrm{~mm} / \mathrm{s}$ (broader for glass). Peaks overlap for these phases, so determination of mineral proportions relies on curve fitting to standardized peak shapes (which are theoretically well understood for some, but not all, lunar soil components [e.g., Nolet et al., 1979]). Contributions from the sextet of magnetic $\mathrm{Fe}^{0}$ and the singlet of nanophase (nonmagnetic) $\mathrm{Fe}^{0}$ are also present in the spectrum. For stoichiometric Fe-bearing compounds such as ilmenite and pyrite, the identification and quantification of specific $\mathrm{Fe}^{2+}$ ions relates directly to the proportions of these minerals among all Fe-bearing phases in a sample. In olivine and pyroxene, $\mathrm{Fe}^{2+}$ concentrations are variable. Analogous to the case for VIS-NIR spectra, one cannot distinguish easily between a high proportion of the Fe-poor member of a solid solution and a low proportion of the Fe-rich member of the solid solution in complex mixtures of minerals. Although $\mathrm{Fe}$ in plagioclase may produce two doublets in its Mossbauer spectrum [Hafner, 1975], the Fe concentration of most lunar plagioclase is too low to produce a significant signal, especially in mixtures. Mössbauer spectroscopy, however, detects ilmenite and native iron, which give little or no Raman or infrared signal.
To capitalize on the strengths of each spectroscopic technique, one might use VIS-IR spectroscopy for imaging and Raman and Mössbauer spectroscopy for detailed mineralogical analysis. The strength of VIS-IR imaging is as a reconnaissance tool to locate samples for further analysis. Raman and Mössbauer spectroscopy then would provide complementary identification and quantification of the major minerals in specific targets within the image area. The strength of Raman spectroscopy on multiphase samples will be the identification and potential quantification of the silicates and minerals containing other oxy-anions, and Mossbauer spectroscopy will provide the same for the Fe-bearing species.

\section{Suggested Configuration of a Raman System for a Planetary Rover}

A Raman instrument consists basically of a source of exciting radiation, an energy analyzer, and a detector. In a roverbased Raman spectrometer these could be the following: A small, low-power, low-noise, diode laser source with a 685$\mathrm{nm}$ line; a spectrograph using axially transmissive, holographic optics; and a charge-coupled device (CCD) detector. A sensor head could transfer the excitation laser beam to the target, and collect the scattered radiation with favorable $180^{\circ}$ scattering geometry. If the sensor head is connected to the spectrograph by an optical fiber and attached to a flexible mechanical arm, it can work as an agile probe to obtain in situ Raman spectroscopic measurements of rocks and soils. A rover arm could point the sensor head vertically and laterally over a wide range of angles that would provide great flexibility of use. The spectrometer (apart from the sensor head) could fit into a $<20-\mathrm{cm}$ cube. Except for the connecting cable and sensor head, the system would have no moving parts. A small instrument such as we envisage, designed for industrial process control, already exists (HoloSpec $\mathrm{f} / 1.8^{\mathrm{TM}}$, Kaiser Optical Systems, Inc.).

We estimate needing $<5 \mathrm{~mW}$ continuous laser beam to obtain the Raman spectrum of a soil in $10 \mathrm{~min}$. The necessary power is easily within the capability of standard spacecraft instruments. We suggest using a diode laser instead of a diode-pumped frequency-doubled Nd:YAG laser (which was used in the LIDAR laser ranger in the Clementine spacecraft [Nozette et al., 1994]) to save the power consumed by twostage pumping. The decrease in Raman sensitivity that would arise from using a red excitation line $(685-\mathrm{nm})$ could be compensated by the reduced fluorescence excited by the longer wavelength; fluorescence might be an obstacle to observing the main Raman spectral features in some situations. In our simulating experiments (using $514.5-\mathrm{nm}$ line of $\mathrm{Ar}^{+}$laser), fluorescence emission occurred from some of the measurement points on the anorthositic fragment.

The rover energy-analyzer subsystem would have high light throughput through use of a holographic notch filter that could reject Rayleigh-scattered photons to an optical density level of $6.0\left(T\left(v_{0}\right)<10^{-6}\right)$ while transmitting $\sim 90 \%$ of the Ramanscattered photons. A holographic transmission grating would have low internal scattering (and thus low stray light) and high transmission efficiency (almost $100 \%$ for $s$-polarized light, $>80 \%$ for unpolarized light). In addition, this grating has very high angular dispersion, and thus greatly reduces the size of the spectrograph. A 2400 line/mm grating with an $85-$ $\mathrm{mm}$ focal-length lens would provide a linear dispersion of 3.4 $\mathrm{nm} / \mathrm{mm}$. It would spread the spectrum $\left(200-1100 \mathrm{~cm}^{-1}\right)$ over a 9-mm distance at the detector position. If received by a $512 \times$ 
$256(19 \times 19 \mu \mathrm{m} /$ pixel $)$ CCD detector, this spread would provide a $4 \mathrm{~cm}^{-1}$ spectral resolution, sufficient for qualitative identification of lunar minerals. The entire spectrograph could fit into a $20-\mathrm{cm}$ cube. Because an on-axis transmissive configuration has inherently fewer, easily corrected aberrations, the spectral resolution would be limited only by the width of the pixel of the CCD detector. Moreover, a high-contrast optical imaging capability could provide nearly diffractionlimited imaging [Battey et al., 1993]. The use of transmissive optics would also make the system relatively insensitive to mechanical vibration or rotational error [Battey and Slater, 1993].

Available CCD detectors with high quantum efficiency in the visible spectral region are in common use for spacecraft applications (e.g., solid-state imaging (SSI) system in Galileo; UV-VIS and high-resolution (HIRES) sensors in Clementine [Belton et al., 1992; Nozette et al., 1994]). As a twodimensional detector, a $\mathrm{CCD}$ can detect multitrack Raman spectra. Combining this feature with the diffraction-limited image capability of the spectrograph and a HoloPlex ${ }^{\mathrm{TM}}$ grating, which can direct different frequency ranges of a Raman spectrum separately to the different rows of a CCD detector, would enable the simultaneous collection of spectra for both mineral and organic species (e.g., $\mathrm{C}-\mathrm{H}, \mathrm{OH}$ ) with good spectral resolution.

\section{Conclusions}

Raman spectroscopy provides unambiguous identification of the major silicate minerals in lunar rocks and regolith fines. The sharp, nonoverlapping peaks are an advantage over VISNIR spectra and MIR spectra. Constraints on Fo contents of olivine can be obtained from peak shifts. Also, Raman spectroscopy yields peaks for plagioclase, for which the other proposed methods provide little or no direct information. Structural types of pyroxene (orthorhombic, monoclinic, or triclinic pyroxenoid) can probably be deduced from peak shapes and positions if laboratory calibration is done. The method holds promise for rough quantitative determination of proportions of feldspar, pyroxene, and olivine in the crystalline components of lunar rocks and soils sensed by on-surface automated analysis. It would also enable identification of many minor minerals if they were locally concentrated or of sufficiently coarse grain size. The method is poorly sensitive to some oxide minerals, such as ilmenite, and insensitive to Fe metal. Thus, Raman and Mössbauer spectroscopy are complementary active surface-analysis techniques.

The Raman system that we envision offers high detection sensitivity, a flexible detection configuration, small size, low power, and low sensitivity to mechanical vibration, making it a suitable and reliable sensor for lunar landers and rovers. It is based on existing spectroscopic techniques, but for a few components, space-rated versions would have to be developed. We have chosen to present the case for its use on the Moon because that is the planetary body of greatest interest to us. It can also be used for robotic exploration of other objects, as a result of its sensitivity to carbonate, sulfate, and phosphate minerals, and to organic molecules.

Acknowledgments. We thank Jill Pasteris for the use of the Raman spectrometer, and Brigitte Wopenka and Jill Pasteris for their advice. We also thank Carlé Pieters, Doug Nash, Dick Morris, and an anonymous reviewer for their comments and suggestions. This work was supported in part by the National Aeronautics and Space Ad. ministration under grant NAGW-3343.

\section{References}

Battey, D. E., and J. B. Slater, Compact holographic imaging spectrograph for process control applications, Proc. SPIE Int. Soc. Opt. Eng., 2069, 60-64, 1993.

Battey, D. E., J. B. Slater, R. Wludyka, H. Owen, D. M. Pallister, and M. D. Morris, Axial transmissive $\mathrm{f} / 1.8$ imaging Raman spectrograph with volume-phase holographic filter and grating, Appl. Spectrosc., 47, 1913-1919, 1993.

Bell, J. F., P. G. Lucey, D. T. Blewett, B. R. Hawke, M. S. Robinson, T. L. Roush, J. D. Bregman, D. M. Rank, D. Harker, and P. Temi, Imaging spectroscopy of the Moon in the mid-infrared: 8.3 to 13.3 $\mu \mathrm{m}$ image cubes of Tycho (abstract), Lumar Planet. Sci., XXVI, 97 98, 1995.

Belton, M. J. S., et al., Lunar impact basins and crustal heterogeneity: New western limb and far side data from Galileo, Sclence, 255, 570-576, 1992.

Burns, R. G., Mineralogical Applications of Crystal Field Theory, 2nd ed., chap. 10, pp. 396-427, Cambridge Univ. Press, New York, 1993.

Dele-Dubois, M. L., P. Dhamelincourt, and H. J. Schubnel, Etude par spectroscopie Raman d'inclusions dans les diamonts, saphirs et émeraudes, Rev. Fr. de Gemmol., 64, 13-16, 1981.

Estep, P. A., J. J. Kovach, P. Waldstein, and C. Karr Jr., Infrared and Raman spectroscopic studies of structural variations in minerals from Apollo 11, 12, 14, and 15 samples, Proc. Lunar Sci. Conf., 3rd, 3047-3067, 1972.

Fabel, G. W., W. B. White, E. W. White, and R. Roy, Structure of lunar glasses by Raman and soft X-ray spectroscopy, Proc. Lunar Sci. Conf., 3rd, 939-951, 1972.

Guyot, F., H. Boyer, M. Madon, B. Velde, and J. P. Poirier, Comparison of the Raman microprobe spectra of $(\mathrm{Mg}, \mathrm{Fe})_{2}, \mathrm{SiO}_{4}$ and $\mathrm{Mg}_{2} \mathrm{GeO}_{4}$ with olivine and spinel structures, Phys. Chem Miner., 13, 91-95, 1986.

Hafner, S. S., Mossbauer spectroscopy in lunar geology and mineralogy, in Topics in Applied Physics, vol. 5. Mössbauer Spectroscopy, edited by U. Gonser, pp. 167-199. Springer-Verlag, New York, 1975

Heiken, G., and D. S. McKay, Petrography of Apollo 17 soils, Proc. Lunar Sci. Conf., Sth, 843-860, 1974.

Jolliff, B. L., and L. A. Haskin, Cogenetic rock fragments from a lunar soil: Evidence of a ferroan noritic-anorthosite pluton on the Moon, Geochim Cosmochim Acta, 59, 2345-2374, 1995.

Jolliff, B. L., R. L. Korotev, and L. A. Haskin, Geochemistry of 2-4 $\mathrm{mm}$ particles from Apollo 14 soil (14161) and implications regarding igneous components and soil-forming processes, Proc. Lunar Planet. Sci., 2I, 193-219, 1991.

Korotev, R. L., Comparative geochemistry of Apollo 16 surface soils and samples from cores 64002 and 60007, Proc. Lunar Planet. Sci. Conf,, 13th, Part 1, J. Geophys. Res., 87, A269-A278, 1982.

McMillan, P., Structural studies of silicate glasses and meltsApplications and limitations of Raman spectroscopy, Am Mineral., 69, 622-644, 1984.

Morris, R. V., The surface exposure (maturity) of lunar soils: Some concepts and $\mathrm{I}_{S} / \mathrm{FeO}$ compilation, Proc. Lumar Planet. Sci. Conf., 9th, 2287-2297, 1978.

Morris, R. V., D. G. Agresti, E. L. Willis, T. D. Shelfer, M. M. Pimperl, M. -H. Shen, and M. A. Gibson, Mossbauer spectroscopy for lunar resource assessment: Measurement of mineralogy and soil maturity, New Technologies for Lunar Resource Assessment, LPI Tech. Rep., 92-06, 39-40, 1992.

Morris, R. V., R. Score, C. Dardano, and G. Heiken, Handbook of Lunar Soils, NASA Johnson Space Center, Houston, 1983.

Nash, D. B., J. W. Salisbury, J. E. Conel, P. G. Lucey, and P. R. Christensen, Evaluation of infrared emission spectroscopy for mapping the Moon's surface composition from lunar orbit, J. Geophys. Res., 98, 23,535-23,552, 1993.

Nolet, D. A., R. G Burns., S. L. Flamm, and J. R. Besancon, Spectra of Fe-Ti silicate glasses: Implications to remote-sensing of planetary surfaces, Proc. Lunar Planet. Sci. Conf., I0th, 1775-1786, 1979.

Nozette, S., et al., The Clementine mission to the Moon: Scientific overview, Sclence, 266, 1835-1839, 1994.

Papike, J. J., L. A. Taylor, and S. B. Simon, Lunar minerals, in Lunar Sourcebook, edited by G. Heiken, D. Vaniman, and B. French, pp. 121-181, Cambridge Univ. Press, New York, 1991.

Perry, C. H., D. K. Agrawal, E. Anastassakis, R. P. Lowndes, and N. E. Tornberg, Far infrared and Raman spectroscopic investigations 
of lunar materials from Apollo 11, 12, 14, 15, Proc. Lunar Sci. Conf., 3rd, 3077-3095, 1972.

Pieters, C. M., Mare basalt types on the front side of the moon: A summary of spectral reflectance data, Proc. Lunar Planet. Sci. Conf., 9th, 2825-2849, 1978

Pieters, C. M., Composition of the lunar highland crust from nearinfrared spectroscopy, Rev. Geophys, 24, 557-578, 1986.

Pieters, C. M., Compositional diversity and stratigraphy of the lunar crust derived from reflectance spectroscopy, in Remote Geochemical Analysis: Elemental and Mineralogical Analysis, edited by C. M. Pieters and P. A. J. Englert, Cambridge Univ. Press, New York, pp. 309-339, 1993.

Pieters, C. M., and G. J. Taylor, Millimeter petrology and kilometer mineralogical exploration of the moon, Proc. Lunar Planet. Sct. Conf, 19th, 115-125, 1989.

Pinet, M., D. C. Smith, and H. Boyer, Raman fingerprinting of opaque and semi-opaque minerals: The natural system geikielite-ilmenitepyrophanite (GIP), Special meeting, Societe Francaise de mineralogie et de cristallographie, Terra Cognita, 7(1), 18, 1986.

Rockow, K. M., B. L. Jolliff, R. L. Korotev, and L. A. Haskin, Geology and distribution of rock types at the Apollo 17 landing site from a 2-4 mm perspective (abstract), Lunar Planet. Sci., $X X V$, $1149-1150,1994$.

Steele, A. M., R. O. Colson, R. L. Korotev, and L. A. Haskin, Apollo 15 green glass: Compositional distribution and petrogenesis, Geochim. Cosmochim Acta, 56, 4075-4090, 1992.

Sunshine, J. M., and C. M. Pieters, Estimating modal abundances from the spectra of natural and laboratory pyroxene mixtures using the modified Gaussian model, J. Geophys. Res., 98, 9075-9087, 1993.

Sweet, J. R., W. B. White, E. W. White, and R. Roy, Structural and mineralogical investigations of lunar glasses and terrestrial glasses by Raman spectroscopy, Proc. Lunar Sci. Conf., 4th, 389-396, 1973.

Wang, A., J. Han, L. Guo, J. Yu, and P. Zeng, Database of standard Raman spectra of minerals and related inorganic crystals, Appl. Specirosc., 48, 959-968, 1994.

White, W. B., E. W. White, H. Gorz, H. K. Henisch, G. W. Fabel, R. Roy, and J. N. Weber, Physical characterization of lunar glasses and fines, Proc. Lunar Sct. Conf., 2nd, 2213-2221, 1971.

Wolfe, E. W., N. G. Bailey, B. K. Lucchitta, W. R. Muehlberger, D. H. Scott, R. L. Sutton, and H. G. Wilshire, The geologic investigation of the Apollo 17 landing site, U.S. Geol. Surv. Prof. Pap. 1080, 280 pp., 1981.

L. A. Haskin, B. L. Jolliff, and A. Wang, Department of Earth and Planetary Sciences and McDonnell Center for the Space Sciences, Washington University, One Brookings Drive, St. Louis, MO 63130. (e-mail: lah@wumoonl.wustl.edu; blj@wumoon3.wustl.edu; alianw@realrock2.wustl.edu)

(Received January 27, 1995; revised July 3, 1995; accepted July 6,1995 .) 
